\title{
Technical and technological investigation of cultural heritage: experience in applications of spectroscopic methods
}

\author{
I.A. Grigorieva ${ }^{1, *}$, K.S. Chugunova ${ }^{1}$, I.F. Kadikova ${ }^{2}$, S.V. Khavrin ${ }^{1}$, and S.A. Pisareva ${ }^{2}$ \\ ${ }^{1}$ The State Hermitage Museum, 190000 Saint Petersburg, Russia \\ ${ }^{2}$ The State Research Institute for Restoration, 107014 Moscow, Russia
}

\begin{abstract}
Physical and chemical methods of analysis are indispensable for restoration, study of painting techniques, examination and attribution of works of art. Development of new directions of investigations as well as improvements in sample preparation allow applying non-destructive analysis methods, minimizing amount of matter used to obtain informative spectra, preventing alteration and destruction of samples in the course of investigation. This paper observes the examples of applying optical and spectral methods, including molecular spectral analysis and electron microscopy, for study of binding media and pigments of painting and archaeological artifacts.
\end{abstract}

Preservation of cultural heritage, study and evaluation of their condition are the main purposes of restoration and research. Therefore, analysis of works of art is realized by means of non-destructive methods, including investigation in visible, infrared, ultraviolet and X-ray light as well as optical microscopy and XRF [1].

The first stage of research involves non-sampling methods, for example, XRF and reflectance spectroscopy - which in some cases are the only possible way to examine works of art such as paper, fabrics, aquarelles and manuscripts. These methods provide the information regarding just the superficial layer. Applying them during investigation of $\mathrm{K}$. Bryullov's drawings from "Italian Album" series apart from frequently used Prussian blue it was identified rare organic pigment Indian yellow (mixture of calcium and magnesium salt of euxantic acid). Indian yellow was used in Europe from late XVIII century till 1908 when its production was restricted [2]; it corresponds to period of the artist' life.

Detailed information about multicomponent multilayer structures (painting, ceramics, archaeological objects etc.) can be obtained only by taking samples and their investigation by a combination of analytical methods. Thus, lead white in the form of unusually large tabular hexahedral crystals was discovered in pictures of K. Malevich by means of polarized light microscopy [3]. SEM-EDX method confirmed lead presence in crystals and determined their size (about $7 \mu \mathrm{m}$ ), and XRD showed that these crystals are composed of hydrocerussite $\left(2 \mathrm{PbCO}_{3} \cdot \mathrm{Pb}(\mathrm{OH})_{2}\right)$.

\footnotetext{
${ }^{*}$ Corresponding author: grigorieva_ia@hermitage.ru
} 
Sampling is another key issue in obtaining relevant results. Thus, micro-ATR and microRaman spectroscopy were chosen as the most suitable methods for study of molecular composition of degraded historic blue-green glass beads because of their dimensions, geometry peculiarities and necessity of their preservation. The main problem was connected with beads fixation on microscope stage and was solved using an Indium plate in which the sample was placed.

Another issue which complicates investigation and interpretation of results is connected with superposed composition of samples. Most museum objects consist of both organic and inorganic compounds, including natural ones with variational chemical composition which are essentially altered due to ageing and restoration interventions. Long-time modeling and artificial ageing don't always lead to understanding of physical and chemical processes which take place for a long period of time and consequent extrapolation doesn't provide reliable estimation of results $[4,5]$, for example, age determination of works of art by means of FTIRspectroscopy.

Multidisciplinary investigation of Russian oil painting of XX century based on lead white and zinc white was carried out. Analysis of calibration dependences of integral intensities of absorption bands at $1740 \mathrm{~cm}^{-1}$ (carbonyl peak) and $1650-1500 \mathrm{~cm}^{-1}$ region (metal carboxylates peaks) on time showed their substantially non-linear behavior [6]. But in course of study a number of technological features of paints preparation was revealed; these features can be used as time markers. For example, it was typical for oil paints based on zinc white of early XX century (up to 30s) the presence of gypsum (from 10 to $50 \%$ ), barium white (up to $20 \%$ ) and lead white (up to $10 \%$ ), and, less commonly, china clay, chalk and talc.

The paper shows the necessity of development of complex approach and strategy for investigation of cultural heritage objects. This allows minimizing negative impact on works of art and obtaining relevant results for different museum tasks.

The support from Russian Foundation for Basic Research is acknowledged (14-0600244).

The support from Russian Science Foundation is acknowledged (16-18-10366).

\section{References}

1. J.P. Mohen, M. Menu, B. Mottin, Mona Lisa: Inside the painting, (Abrams, New York, 2006)

2. N.S. Baer, A. Joel, R. L. Feller, N. Indictor, Artists Pigments: A Handbook of their History and Characteristics (Cambridge University Press, Oxford, 1986)

3. S. Pisareva, XV Scientific Conference Expertise and Attribution of Works of Fine Arts (Moscow, 2014)

4. J. van der Weerd, R.M.A. Heeren, Stud. Conserv. 49, 193 (2004)

5. C. Miliani, F. Rosi, A. Daveri, Appl. Phys. A 106, 295 (2012)

6. I.A. Balahnina., N.N. Brandt, A.Y. Chikishev, Y.I. Grenberg, I.A. Grigorieva, I.F. Kadikova, S.A. Pisareva, Appl. Spectr. 70, 1150 (2016) 